\title{
Study of a micro-structured PHE for the thermal management of a Fuel Cell
}

\author{
Ioannis A. STOGIANNIS, Aikaterini A. MOUZA, Spiros V. PARAS* \\ * Corresponding author: Tel.: ++30 2310 996174; Fax: ++30 2310996209 \\ Email: paras@cheng.auth.gr \\ Chemical Engineering Department, Aristotle University of Thessaloniki, GR
}

\begin{abstract}
In the constantly growing market of fuel cells, the heat management of the system is a crucial area of research, since it affects the efficiency, operability and lifetime of the fuel cell. The CFD simulations performed for a plate heat exchanger $(P H E)$ with flat plates clearly demonstrate temperature non-uniformity across the membrane of the unit cell. The $C F D$ code was successfully validated with experimental data acquired from a setup that reproduces the geometry and simulates the thermal behaviour of a typical unit $P E M F C$. Additionally, the performance of a novel PHE, with micro-structured corrugations on its plates, was studied with the previously validated $C F D$ code. The results clearly show that the proposed plate modifications can increase temperature uniformity across the membrane more than $20 \%$ compared to that of the flat plate.
\end{abstract}

Keywords: Fuel cells, Heat management, $C F D$.

\section{Introduction}

Global energy market, due to high concern about fossil fuel depletion and climate change, has paid significant attention to clean energy alternatives. Hydrogen has been pointed out as one of the most promising energy carriers, as it can be produced through both traditional industrial and renewable routes. Fuel cells play a dominant role in the future hydrogen economy as they are electrochemical devices that directly convert the chemical energy of hydrogen into electrical energy. Polymer electrolyte membrane fuel cells (PEMFCs) are the key energy convertors applied not only for portable but also for low-power stationary applications. Due to high voltage requirements of most applications, stacks of fuel cells have to be employed in most of cases.

Although research concerning fuel cells was intensive during the last two decades, it has been mainly focused on the technology of the membrane and the electrochemical phenomena that take place inside the cell. Nevertheless, a fuel cell stack may be very complicated due to the specific requirements for high power output and thus a detailed design of the major system components is a critical concern of ongoing research (Kandlikar and Lu, 2009). Heat management of the fuel cell stack has been pointed out recently as one of the critical de- sign issues to be solved before commercialisation of fuel cell technology (Basu, 2007).

Under normal electric load a $P E M F C$ has an energy efficiency of about 50\% (O'Hayre et al., 2009), while the remaining energy content of hydrogen is transformed into waste heat, which must be effectively removed and used. Heat is generated in a Fuel Cell mainly due to the following reasons:

- Entropy losses associated with the electrochemical reaction.

- Activation losses due to reaction kinetics.

- Ohmic heat production from both the proton current and the electron current.

As a result the sum of the heat sources is analogous to the power output of a PEMFC. Recovery of the waste heat produced by fuel cells especially in micro-cogeneration facilities has been an interesting alternative to traditional approaches (Wang et al., 2011). An exergy comparison has showed that the PEMFCbased system uses the fuel energy input more efficiently than other fuel cell-type systems (Barelli et al., 2011). Several researchers have proposed heat recovery units for residential applications (Arsalis et al., 2011; Hwang et al., 2010), thermal coupling of hydride storage tanks (Forde et al., 2009; Pfeifer et al., 2009; Visaria et al., 2011) and space heating in automotive applications. 
The efficient design of a proper cooling system for a $P E M F C$ stack is challenging mainly because of the low driving force between the cooling fluid and the stack temperature, which for normal operating conditions is $60-80{ }^{\circ} \mathrm{C}$. As a result an optimum design of mini-scale compact heat exchangers, based on wellestablished procedures for industrial compact heat exchangers (Kanaris et al., 2009) is a definite market need. Besides heat recovery, another critical issue, often overlooked, is the temperature distribution along the membrane. A temperature non-uniformity has a significant impact on the water content of the membrane and correspondingly on its lifetime (Kandlikar and Lu, 2009).

To the authors' best knowledge, research studies concerning the rheological characteristics of the flow of the coolant in the narrow channels of the cooling loops of PEMFC are limited. Lasbet et al. (2007) have numerically studied the flow in a chaotic mini-channel, constructed to pass through special bipolar plates for fuel cell cooling. Senn \& Poulikakos (2004) introduced a comparison study between a tree-like net of cooling channels and common serpentine passages based on the fractal network theory. A common practice in both approaches is to study a unit cell (i.e., a single membrane with the cooling unit on it) and to extrapolate the results to assess the thermal behaviour of multiple cells in a PEMFC stack.

The objective of the present research study is the design and optimisation of a microstructured compact cooling unit for recovering the heat generated by PEMFC stacks. First, to assess the thermal behaviour of a unit PEMFC, an experimental apparatus that adequately simulates both the heat generation and the cooling is designed and constructed. The experimental results are then used to validate a $C F D$ code that simulates a generic geometry for cooling PEMFC applications. Moreover, in order to enhance heat transfer, cooling plates equipped with flow disrupting micro-structured corrugations are numerically tested. Finally, seeking the optimal solution, a parametric study taking into account the geometrical characteristics of the plates is performed based on Design of Experiment ( $D O E$ ) technique.

\section{Experimental Setup}

For this study, an experimental apparatus that reproduces the geometry and "simulates" the thermal behaviour of a typical unit PEMFC has been fabricated, while the electrochemical phenomena are not considered. In place of the Membrane Electrode Assembly a thin thermal plate (Minco Foil Heater) has been positioned. A schematic of the geometry is shown in Figure 1 while the heat exchanging set-up is presented in Figure 2.

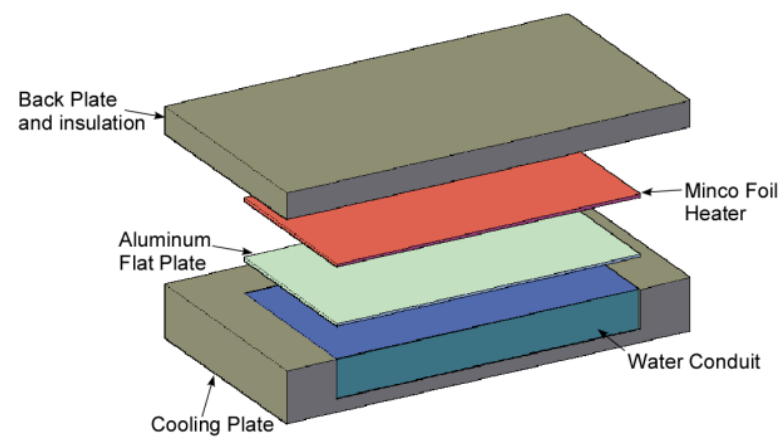

Figure 1 Schematic representation of the experimental unit simulating the thermal behaviour of a FC unit.

It is assumed that the unit cell produces practically equal amounts of heat from both sides and thus only one of the membrane sides needs to be studied. By applying a controllable voltage it is possible to impose a uniform heat flux over the total area $\left(84.5 \mathrm{~cm}^{2}\right)$ of the heating pad. Heat transfer from the "virtual membrane" to the cooling liquid is performed through a $3 \mathrm{~mm}$ thick aluminium plate. The thermal conductivity of the plate is identical to that of the plates used for constructing cooling systems in PEMFC stacks. Using a common thermoplastic material (Polyoxymethylene Acetal) a conduit for the cooling fluid, with a height of $3 \mathrm{~mm}$ is constructed. The proposed geometry allows the cooling fluid to fill the conduit and thus heat is transferred only through the aluminium flat plate. The cooling fluid is provided by a constant temperature bath (Neslab RTE-221) and is circulated by a centrifugal pump. The temperature of the bath is controlled with an accuracy of $0.1{ }^{\circ} \mathrm{C}$, while the flow rate of the cooling water is adjusted using a high-accuracy valve and is measured by an electro-optical flow meter (McMillan, $S$ 111). Temperature measurements on the plate are performed using surface thermocouples 
(Surface Mount CO1) of type K, while the temperature of the cooling liquid outlet is measured by a type $K$ thin thermocouple $\left(\right.$ Omega $\left.{ }^{\circledR}\right)$.

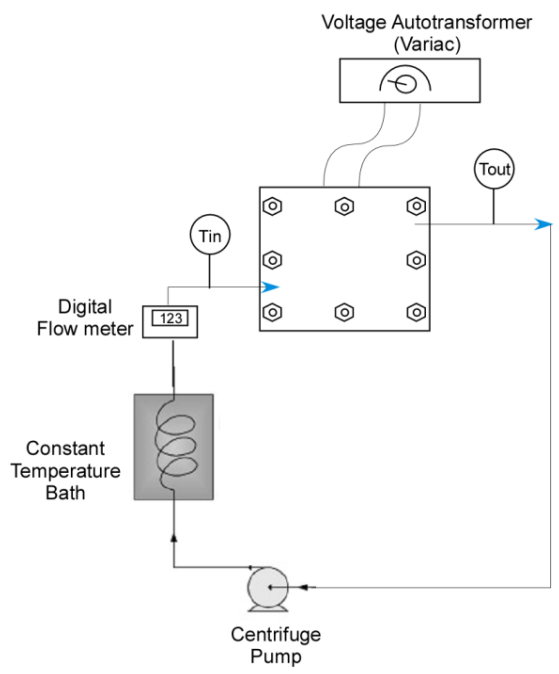

Figure 2 Set-up of the experimental unit with all the key components.

A photo of the experimental set-up and the position of the thermocouples is shown in Figure 3. The thermocouples, whose accuracy has been estimated to be $\pm 0.2{ }^{\circ} \mathrm{C}$, are con-

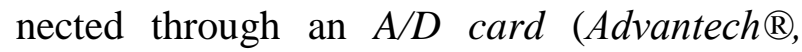
$P C I-1710 H G)$ to a $P C$ for temperature monitoring and recording.

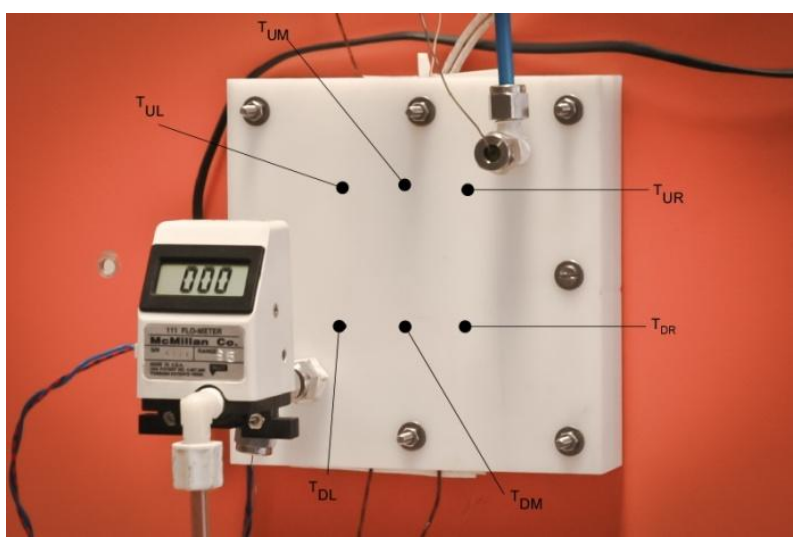

Figure 3 Photo of the experimental unit. The positions of the six thermocouples are indicated.

During each experiment the flow rate of the cooling fluid is initially set, voltage is applied to the heating pad and after steady state is achieved, six temperatures are recorded. Then, the cooling liquid flow rate is increased and new data are collected. Experiments were conducted for a set of flow rates between 100 and $250 \mathrm{ml} / \mathrm{min}$.

\section{Numerical Calculations}

A CFD code (ANSYS CFX $\left.X^{\circledR} 13.0\right)$ is employed to visualise the velocity field, and the temperature distribution on the plate as well as to calculate heat transfer characteristics. The cooling plate surface might be either flat or imposed with corrugated patterns.

The flow of the cooling liquid is considered fully developed at the inlet, while no-slip condition is assumed for the walls of the water conduit. Since the flow is considered laminar Direct Numerical Solution is employed. Each computational model, with different geometrical configurations, is constructed using the parametric design features of ANSYS Workbench $^{\circledR}$. Employing the Design Exploration features of the software a detailed set of 23 "computational experiments" has been designed based on the Box-Behnken technique, a well-established $D O E$ method.

Four dimensionless groups are selected as the design variables (Figure 4), namely:

- The step to height ratio $(d / H)$ that expresses the portion of the cooling channel filled with the corrugation's height.

- The corrugation aspect ratio $(l / d)$ defined as the length of the step divided by its height.

- The dimensionless offset (off/x) between two consecutive corrugations on the same plate, defined as the distance between the corrugations to the total length of the plate.

- The Reynolds number inside the conduit, $R e=u d \rho / \mu$, where the characteristic length is the height $(d)$ of the corrugation.

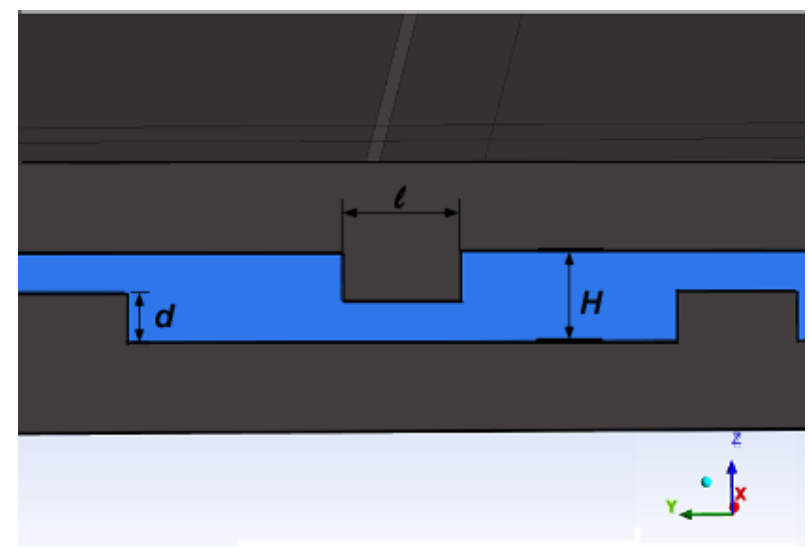

Figure 4 Geometric parameters of a part of the computational domain. 
The computational grid is an unstructured mesh constructed with Ansys Mesh capabilities using the Delauny method. For the appropriate representation of fluid flow and heat transfer near the solid wall, a layer of prism elements (also known as "inflated" layers) is imposed in the vicinity of the walls. Three distinct computational domains were used: one for the simulation of cooling liquid, one (with two parts) for the solid cooling plates and one for the foil heater. The working fluid i.e. water that enters the conduit along the $z$-direction (Figure 5), and has an entrance temperature of $40{ }^{\circ} \mathrm{C}$ in all simulations. The use of different domains allows the user to optimise the density of the grid based on the computational needs of the specific geometry studied. As the quality of the mesh is critical for the accuracy of the simulations, it is examined and modified especially in the small passages of the water conduit in order to speed up convergence and to increase accuracy. Due to high computational needs a high-performance unit for parallel computing is employed consisting of 24 Intel Opteron cores with $24 \mathrm{~GB}$ of RAM which runs on a Gentoo Linux distribution. The wall clock time needed for each simulation run varies from 8 to 16 hours and depends mainly on the mesh density of each computational model.
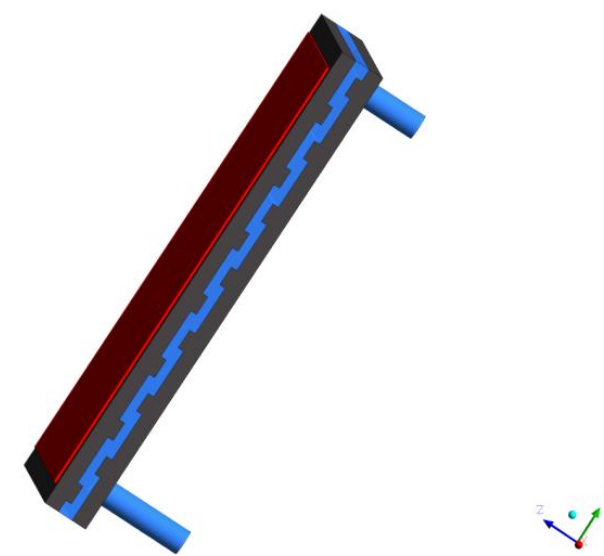

Figure 5 Representation of the computational geometry.

In order to achieve an optimum grid density a grid dependence study has been performed. Two critical parameters, namely the outlet temperature of the cooling liquid $\left(T_{c w, o u t}\right)$ and the pressure drop along the conduit have been chosen to be compared between different simulations and for the various $R e$ studied. Typical results for $R e=90$ are presented in Table 1 .
Table 1 Grid dependence study for a typical Re=90

\begin{tabular}{rcc}
\hline $\begin{array}{l}\text { Grid Density } \\
\text { (fluid section) }\end{array}$ & $\begin{array}{c}\boldsymbol{T}_{\boldsymbol{c} w, \text { out }} \\
\left({ }^{\circ} \mathrm{C}\right)\end{array}$ & $\begin{array}{c}\text { Pressure Drop } \\
(\mathrm{Pa})\end{array}$ \\
\hline 650,000 & 45.4 & 11 \\
$1,250,000$ & 45.7 & 8 \\
$\mathbf{1 , 7 0 0 , 0 0 0}$ & $\mathbf{4 6 . 1}$ & 7 \\
$2,300,000$ & 46.1 & 7 \\
\hline
\end{tabular}

\section{Experimental \& Numerical Results}

Appropriate voltage is applied on the foil heater using an autotransformer in order to produce a stable heat flux of $0.5 \mathrm{~W} / \mathrm{cm}^{2}$. The thermal energy produced corresponds to a fuel cell of $42 \mathrm{~W}$. This level of power output is typical for a fuel cell unit with a Membrane Electrode Assembly area of around $80 \mathrm{~cm}^{2}$, i.e., equivalent to that of the foil heater used in the experimental unit.

Firstly, the thermal energy that is recovered in the cooling fluid is computed using the total energy balance:

$$
Q=m c_{p} \Delta \mathrm{T}_{c w}
$$

where $m$ is the mass flow rate of the cooling water, $c_{p}$, the heat capacity of the water and $\Delta T_{c w}$ the measured temperature difference between the inlet and the outlet of the cooling water.

As it is obvious from Table 2, it is possible to efficiently cool the $P E M F C$ and recover the heat dissipated from the foil heater with the experimental set-up constructed in our Lab. Local temperature measurements serve a dual purpose; they can provide useful coarse insights of "hot spots" that can lead to degradation of membrane and, on the other hand, can provide results that can be used for validating the $C F D$ simulations.

Table 2 Heat recovered from the PEMFC unit for different cooling water flow rates.

\begin{tabular}{cccc}
\hline $\begin{array}{c}\text { Flow Rate } \\
(\mathrm{ml} / \mathrm{min})\end{array}$ & $\begin{array}{c}\boldsymbol{T}_{\boldsymbol{c}, \text {,in }} \\
\left({ }^{\circ} \mathrm{C}\right)\end{array}$ & $\begin{array}{c}\boldsymbol{T}_{\boldsymbol{c}, \text { out }} \\
\left({ }^{\circ} \mathrm{C}\right)\end{array}$ & $\begin{array}{c}\text { Heat } \\
\text { recovered }\end{array}$ \\
\hline 100 & 40.0 & 45.9 & $97.2 \%$ \\
150 & 40.0 & 44.0 & $99.2 \%$ \\
250 & 40.0 & 42.4 & $98.1 \%$ \\
\hline
\end{tabular}

In Figure 6 a typical comparison of temperatures measured by the thermocouples and the ones computed by the $C F D$ code is presented. 
The $X Y$ coordination of the thermocouple locations on the plate is also included in the graph.

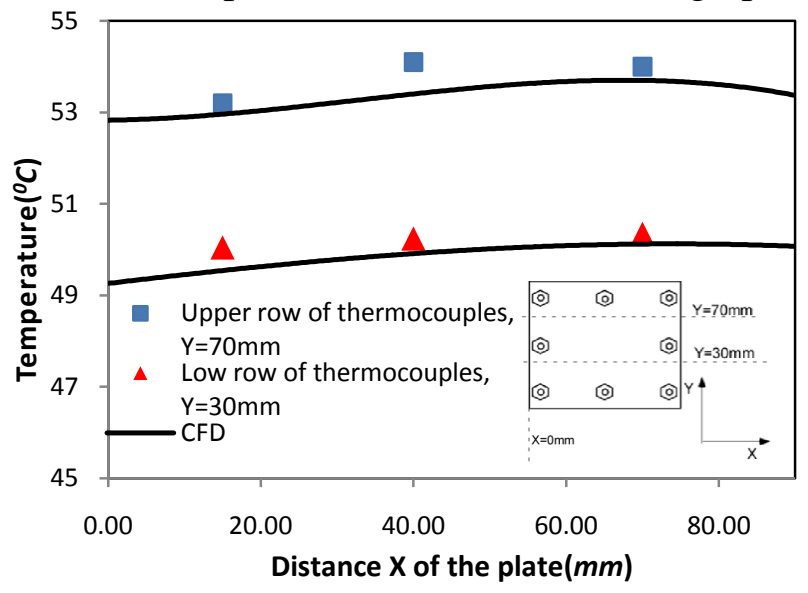

Figure 6 Local temperature measurements on the "virtual membrane" and validation of the CFD code.

The numerical results are in fairly good agreement with the experimental ones. Data from the numerical simulations are given in Figure 7, where a typical temperature distribution on the "virtual membrane" is presented (for water flow rate $100 \mathrm{ml} / \mathrm{min}$ ). It is obvious that the temperature is not uniformly distributed over the plate, while the temperature difference reaches $7{ }^{\circ} \mathrm{C}$. Two major areas of locally increased temperature can be readily distinguished, i.e., the upper part of the plate (above $Y=60 \mathrm{~mm}$ ) and the bottom of the plate (above $X=70 \mathrm{~mm}$ ).

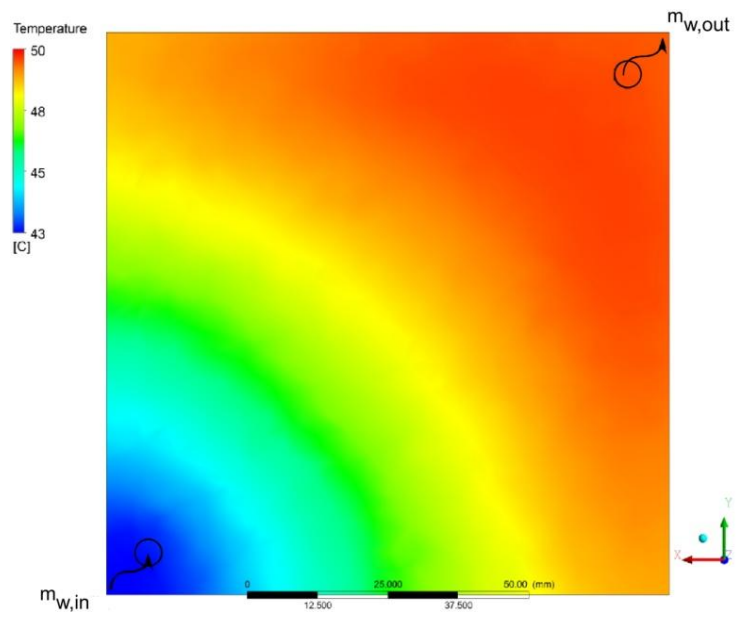

Figure 7 Temperature distribution and non-uniformity on the "virtual membrane", cooling water flow rate $100 \mathrm{ml} / \mathrm{min}$.

The velocity distribution of the cooling liquid (Figure 8) shows that the "hot spots" identified on the surface of the "virtual membrane" correspond to the areas where cooling fluid has very low or even zero velocities. An analogous result, for compact plate heat exchangers has also been reported in a relevant study by Kanaris et al. (2009).

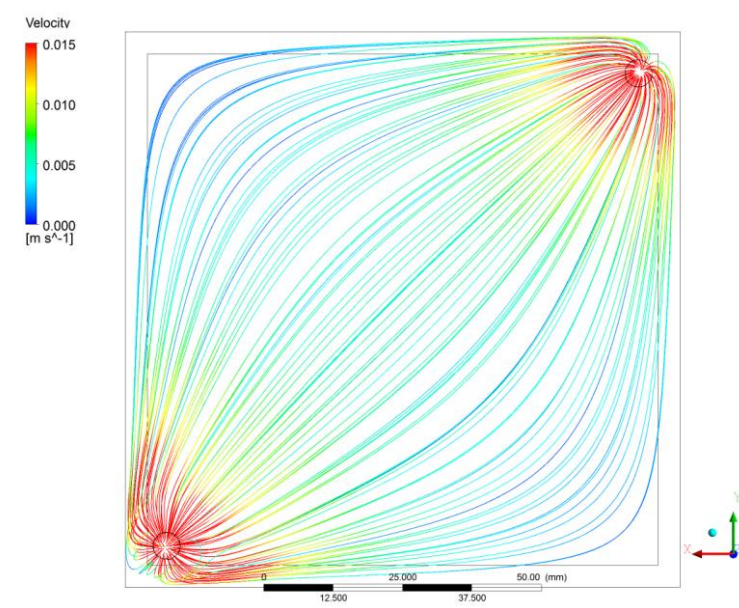

Figure 8 Typical flow field of the cooling water inside the conduit for a flat cooling plate.

The way in which the cooling liquid enters the conduit is another important issue. Since the non-uniformity of the temperature distribution, observed in both experimental and computational results, can be attributed to the fact that the cooling liquid enters through a single entrance, a multi-inlet configuration seems to be a feasible solution. Thus a multi-inlet conduit is designed and numerically studied.

\section{Modification of the cooling plate}

During the quest for heat transfer enhancement in plate heat exchangers, one of the most promising fields of research is the study of the effect of corrugations imposed on the surface of the plates. It is known that an undulated surface results in flow separation and reattachment and thus augments heat transfer rates. This heat transfer enhancement is inevitably accompanied by a substantial increase in pressure drop. However, in fuel cell applications the key issue is to achieve a practically uniform temperature distribution along the membrane. This can be accomplished by suitably modifying the cooling liquid flow field.

The $C F D$ code, previously validated in a unit $P E M F C$, is used in this computational study that aims to optimise the geometrical characteristics of a cooling plate employed with flow disrupting corrugations. 
Table 3 Constraints of the design variables.

\begin{tabular}{ccc}
\hline Parameter & Lower Limit & Upper Limit \\
\hline$d / h$ & 0.4 & 0.7 \\
$l / d$ & 2 & 4 \\
offset & 0.14 & 0.28 \\
Re & 90 & 170 \\
\hline
\end{tabular}

As it has been already mentioned, a threeinlet approach is chosen in order to reduce the area of hotspots and enhance temperature uniformity over the "virtual membrane".

Design specifications that are commonly used in heat transfer equipment have been taken into account in order to select the upper and lower bound of each dimensionless group chosen as design variable. Namely, the height to step ratio $(d / h)$ is limited to 0.7 , since a higher value leads to almost complete blockage of the water conduit and also to poor performance of the grid algorithm in the small passages constructed in higher values of the variable. As for the corrugation aspect ratio the upper limit is set to 2 and the lower limit is set to 4 . For the dimensional offset between two consecutive corrugations a routine has been built and implemented in Ansys Geometry in order to ensure that the corrugations constructed are placed fully on the surface of the plate. A summary of all design variables limits is given in Table 3.

To optimise the performance of a PEMFC stack cooling unit, both the uniformity of the temperature on the "virtual membrane" and the corresponding friction losses must be considered. The concept of an Index of Uniform Temperature (IUT) proposed by Chen et al. (2003) and used in similar studies, quantifies the uniformity of temperature over a surface $A$.

$$
I U T=\frac{\int_{A}\left|T-T_{\text {avg }}\right| d A}{\int_{A} d A} \text { and } T_{\text {avg }}=\frac{\int_{A} T d A}{\int_{A} d A}
$$

In the present case $A$ is the surface area of the "virtual membrane". It is obvious that IUT becomes zero when the temperature is constant throughout the heat transfer area. Consequently, a thermal-related quantity, $n_{U T}$ that expresses the temperature uniformity on the corrugated plate $(I U T)$, with respect to that on a flat one (i.e., without corrugations) $\left(I U T_{0}\right)$ is defined as:

$$
n_{U_{T}}=\left(\frac{I U T}{I U T_{0}}\right)
$$

Similarly, a friction-related term $\left(n_{f}\right)$ based on the well-established friction factor, $f$, is formulated:

$$
f=\frac{\Delta P}{L} \frac{D_{h}}{\rho u^{2} / 2} \text { and } n_{f}=\left(\frac{f}{f_{0}}\right)
$$

where $D_{h}$ the hydraulic conduit diameter.

Baek et al. (2011) have proposed a PEMFC cooling unit with coolant flow channels of different designs and they report that the IUT values range from 10 to 1.4. Giddey et al. (2004) suggest that a temperature difference even up to $25{ }^{\circ} \mathrm{C}$ on the surface of a PEMFC stack can be considered satisfactory.

Typical results of the present study are given in Table 4. A significant improvement in temperature uniformity over the "virtual membrane" can be observed for certain sets of design variables. Offset, i.e. the parameter that expresses the total number of corrugations on the surface of the plate, significantly affects the IUT. When the offset parameter is set between 0.17 and 0.24 , an acceptable uniformity (i.e., low IUTs) is achieved. At lower values of offset $(<0.17)$ the majority of the cooling liquid "flows over" the array of corrugations without significant flow disruption, while at higher values of the parameter $(>0.24)$ the effect of the modifications is practically negligible.

Table 4 A sample set of results for different values of the design variables.

\begin{tabular}{c|c|c|c|c|c|c}
\hline offset & $\boldsymbol{d} / \boldsymbol{H}$ & $\boldsymbol{l} / \boldsymbol{d}$ & $\begin{array}{c}\boldsymbol{I U T} \\
(K)\end{array}$ & $\begin{array}{c}\text { Uniformity } \\
\text { Increase } \\
(\%)\end{array}$ & $\begin{array}{c}\Delta P \\
(P a)\end{array}$ & $\boldsymbol{n}_{f}$ \\
\hline 0.14 & 0.4 & 3 & 1.53 & 4.4 & 9.9 & 1.18 \\
0.14 & 0.6 & 4 & 1.55 & 3.1 & 14.6 & 1.34 \\
0.17 & 0.4 & 3 & 1.48 & 7.5 & 8.6 & 1.13 \\
0.17 & 0.6 & 4 & 1.24 & 22.5 & 15.8 & 1.38 \\
0.21 & 0.4 & 3 & 1.41 & 11.9 & 7.6 & 1.08 \\
$\mathbf{0 . 2 1}$ & $\mathbf{0 . 7}$ & $\mathbf{3}$ & $\mathbf{1 . 2 1}$ & $\mathbf{2 4 . 4}$ & $\mathbf{1 3 . 5}$ & $\mathbf{1 . 3 1}$ \\
0.24 & 0.7 & 3 & 1.24 & 22.5 & 9.9 & 1.18 \\
0.28 & 0.7 & 3 & 1.47 & 8.1 & 8.2 & 1.11 \\
\hline
\end{tabular}


On the other hand, increase of the parameter $d / H$ leads to considerable increase in flow disruption and correspondingly to an improvement of the temperature uniformity on the "virtual membrane".

The effect of the proposed modifications on the flow field of the cooling liquid and, as a result, on the temperature uniformity can be attributed to the generation of lateral velocity components and the breakage of boundarylayer, before and after each flow obstruction. A typical vector field, depicting the velocities of the fluid, is shown in Figure 9.

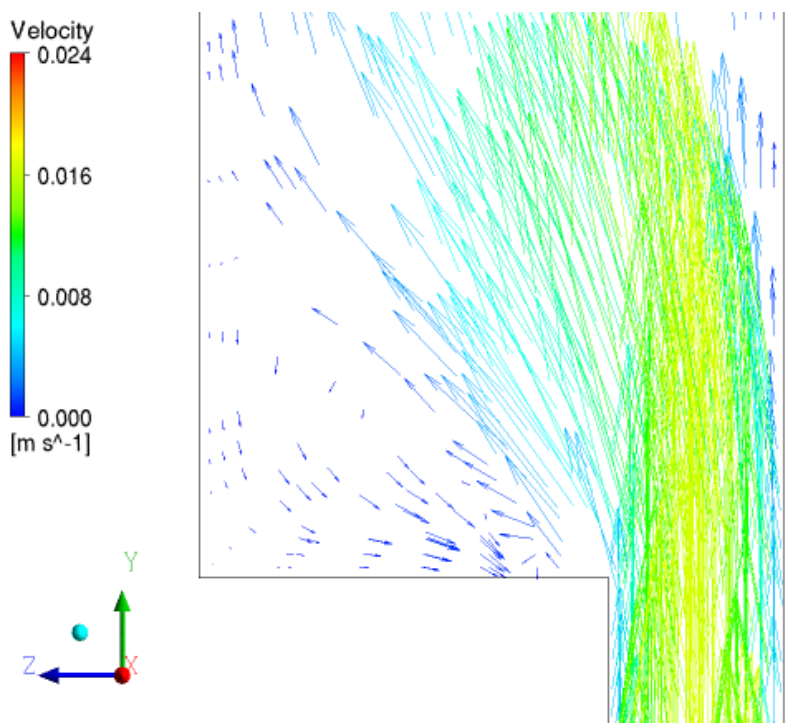

Figure 9 Generation of secondary flows in a typical water conduit employed with corrugations.

It must be pointed out that the increase in pressure drop is relatively small compared to the improvement of temperature uniformity. For small scale application, where PEMFC stacks consist of 50-100 cells the total pressure drop for corrugated plates can reach 0.15 bar, while a flat plate would exhibit pressure drop of about 0.05 bar.

In Figure 10 the temperature distribution on a plate with corrugations (the best design from the set of results, Figure 10b) is compared with that of the base case (Figure 10a), i.e., flat plate with three inlets design. It is obvious that the proposed design greatly improves the temperature uniformity over the "virtual membrane".

To summarise, the results of the present study can be used as a rough guideline for designing compact heat exchangers for $P E M F C$ stacks. Furthermore, the use of optimisation tools, like the Response Surface Methodology $(R S M)$, is expected to provide a general methodological framework for the optimal design of this type of equipment.

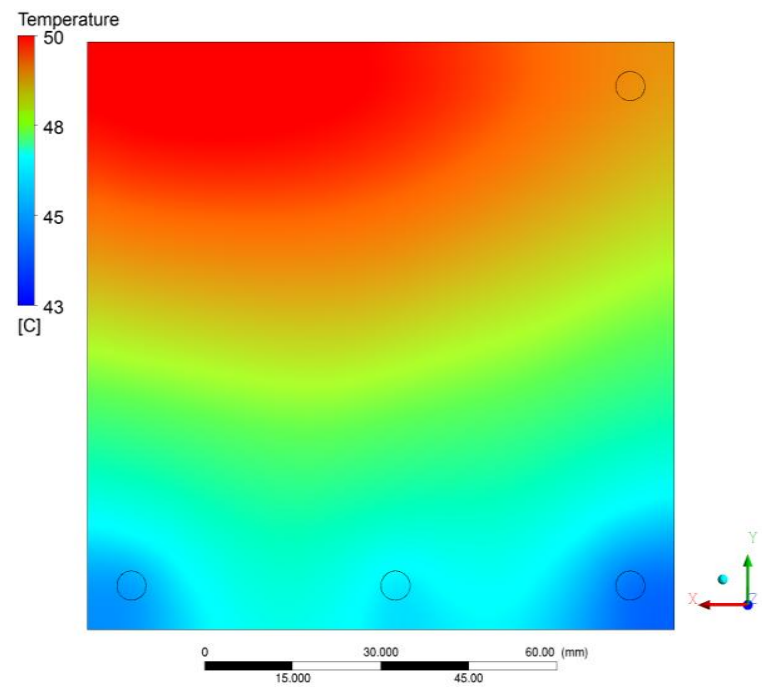

(a)

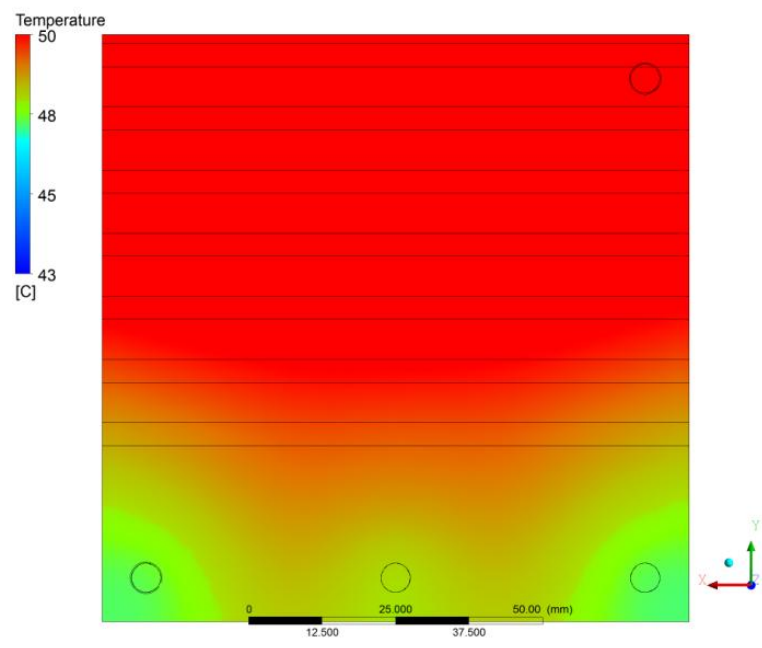

(b)

Figure 10 Temperature distribution and uniformity: a) flat plate $(I U T=1.6 \mathrm{~K})$ and $b)$ corrugated plate $(I U T=1.21)$ for Offset $=0.21, d / H=0.7$ and $l / d=3$.

\section{Conclusions}

A $C F D$ code was employed for the study of a cooling unit of a PEMFC stack. The code was validated with relevant experimental results, also acquired during this study in a unit $P E M F C$. A common DOE technique was used for planning the experiments.

Flow disrupting corrugations were constructed on the surface of a cooling plate in order to achieve uniform temperature distribu- 
tion on the membrane of the fuel cell by enhancing heat transfer in identified "hot spots". The results showed that the modification of cooling water flow field, initiated by the corrugations, can locally increase heat transfer coefficients and correspondingly augment heat transfer. Proposed plate modifications can increase temperature uniformity across the membrane by more than $20 \%$ compared to a flat plate.

The optimisation study of the geometrical characteristics of the corrugations suggests that a higher $d / h$ value leads to an important enhancement of temperature uniformity. It has also been shown that an increase of the number of corrugations up to a critical value improves temperature uniformity while further increase of the corrugations has no significant effect on uniformity.

As this work, which is still in progress, is the first part of a wider research project concerning heat management of low-temperature applications like the PEMFC stacks, the achieved improvement can be considered satisfactory. Future considerations can include the implementation of the constructal theory in the designing pattern of the corrugations on the cooling plates.

Acknowledgements: Authors would like to thank the Lab technicians, Mr. A. Lekkas, Mr. F. Lambropoulos and Mr. T. Tsilipiras for the construction and installation of the experimental apparatus. Contribution and fruitful comments of Dr. A.G. Kanaris are also gratefully acknowledged.

\section{References}

Arsalis, A., Nielsen, M.P., Kær, S.K., 2011. Modeling and off-design performance of a $1 \mathrm{kWe}$ HT-PEMFC (high temperature-proton exchange membrane fuel cell)-based residential micro-CHP (combined-heat-and-power) system for Danish single-family households. Energy 36, 993-1002.

Baek, S.M., Yu, S.H., Nam, J.H., Kim, C.J., 2011. A numerical study on uniform cooling of largescale PEMFCs with different coolant flow field designs. Appl Therm Eng 31, 1427-1434.

Barelli, L., Bidini, G., Gallorini, F., Ottauiano, A., 2011. An energetic-exergetic comparison between PEMFC and SOFC-based micro-CHP systems. Int J Hydrogen Energ 36, 3206-3214.
Basu, S., 2007. Recent trends in fuel cell science and technology. Springer, New York.

Chen, F.C., Gao, Z., Loutfy, R.O., Hecht, M., 2003. Analysis of Optimal Heat Transfer in a PEM Fuel Cell Cooling Plate. Fuel Cells 3, 181-188.

Forde, T., Eriksen, J., Pettersen, A.G., Vie, P.J.S., Ulleberg, O., 2009. Thermal integration of a metal hydride storage unit and a PEM fuel cell stack. Int J Hydrogen Energ 34, 6730-6739.

Giddey, S., Ciacchi, F.T., Badwal, S.P.S., 2004. Design, assembly and operation of polymer electrolyte membrane fuel cell stacks to 1 kW(e) capacity. J Power Sources 125, 155-165.

Hwang, J.J., Zou, M.L., Chang, W.R., Su, A., Weng, F.B., Wu, W., 2010. Implementation of a heat recovery unit in a proton exchange membrane fuel cell system. Int $J$ Hydrogen Energ 35, 8644-8653.

Kanaris, A.G., Mouza, A.A., Paras, S.V., 2009. Optimal design of a plate heat exchanger with undulated surfaces. International Journal of Thermal Sciences 48, 1184-1195.

Kandlikar, S.G., Lu, Z.J., 2009. Thermal management issues in a PEMFC stack - A brief review of current status. Appl Therm Eng 29, 1276-1280.

Lasbet, Y., Auvity, B., Castelain, C., Peerhossaini, H., 2007. Thermal and hydrodynamic performances of chaotic mini-channel: Application to the fuel cell cooling. Heat Transfer Engineering 28, 795-803.

O'Hayre, R.P., Cha, S.-W., Colella, W.P., Prinz, F.B., 2009. Fuel cell fundamentals, 2nd ed. J. Wiley \& Sons, Hoboken, NJ.

Pfeifer, P., Wall, C., Jensen, O., Hahn, H., Fichtner, M., 2009. Thermal coupling of a high temperature PEM fuel cell with a complex hydride tank. Int J Hydrogen Energ 34, 34573466.

Senn, S.M., Poulikakos, D., 2004. Laminar mixing, heat transfer and pressure drop in tree-like microchannel nets and their application for thermal management in polymer electrolyte fuel cells. J Power Sources 130, 178-191.

Visaria, M., Mudawar, I., Pourpoint, T., 2011. Enhanced heat exchanger design for hydrogen storage using high-pressure metal hydride: Part 1. Design methodology and computational results. Int J Heat Mass Tran 54, 413-423.

Wang, Y., Chen, K.S., Mishler, J., Cho, S.C., Adroher, X.C., 2011. A review of polymer electrolyte membrane fuel cells: Technology, applications, and needs on fundamental research. Appl Energ 88, 981-1007. 